\title{
The Mediating Effect of Employee Engagement between Its Antecedents and Consequences
}

\author{
Ahmad A. Al-Tit, Ph.D. \\ Department of Business Administration, College of Business \& Economics (CBE) \\ Qassim University, KSA \\ P.O. Box 6633, Code No.: Buraidah 15452 \\ Tel.96-616-380-0050 Ext.3060 E-mail: aa.altit@qu.edu.sa, ahmteet@yahoo.com \\ Mohammad Hunitie, Ph.D. \\ Department of Public Administration, Faculty of Economics and Administration \\ King Abdulaziz University, KSA \\ E-mail: mohammadhunitie@live.com
}

Received: July 4, $2015 \quad$ Accepted: August 7, $2015 \quad$ Published: October 1, 2015

doi:10.5296/jmr.v7i5.8048 URL: http://dx.doi.org/10.5296/jmr.v7i5.8048

\begin{abstract}
The aim of this study was to identify the mediating effect of employee engagement in the relationship between its antecedents and consequences (i.e. job satisfaction). A random sample comprising 250 subjects from academic institutions in Jordan was used to collect the required data. Of the 250 questionnaires distributed, 238 were returned and considered valid for analysis. The findings showed that all mediation conditions were verified. That is, employee engagement mediated the relationship between employee communication, clear career growth opportunities, employees' pride in their organization, managers' trust and integrity, rewards and recognition, feedback and mentoring, work motivation, psychological empowerment, internal corporate social responsibility (CSR) practices, organizational and supervision support and organizational justice, as well as organizational culture and job satisfaction. Hence, managers should take these antecedents into account to keep their employees engaged and satisfied.
\end{abstract}

Keywords: Employee Engagement, Antecedents, Consequences, Job Satisfaction, Corporate Social Responsibility, Motivation, Empowerment, Organizational Culture 


\section{Introduction}

Employee engagement has been considered a source of competitive advantage (Khan, 1990; Sarwar \& Abugre, 2013) or an antecedent of productivity (Schaufeli\& Bakker, 2004). Sze and Angeline (2011) showed employee engagement to be related to organizational outcomes such as employees' productivity, creativity and innovativeness. They found strong relationships between employees' perceptions of supervisor support, organizational justice and employees' participation in decision-making processes. Suharti and Suliyanto (2012) argued that the great attention paid to employee engagement is due to its effects on organizational outcomes such as performance. Moreover, according to Kumar and Swetha (2011), with employee engagement, employees are more satisfied with their jobs, more committed to their organization, have lower intention to quit and exhibit increased citizenship behaviour. Coetzee and De Villiers (2010) highlighted the significance of employee engagement in employee satisfaction. Similarly, Orgambídez-Ramos, Borrego-Alés, and Mendoza-Sierra (2014) and Moura, Orgambídez-Ramos and Gonçalves (2014) regard engagement as a construct that is an antecedent of job satisfaction.

Saks (2006) draws attention to the inputs and outputs of employee engagement that result in engaged employees. For him, support (organizational or supervisory) and justice are among the antecedents of employee engagement, whilst one consequence is organizational citizenship behaviour. Rasheed and Khan (2013) identified four antecedents of employee engagement: supervisor support, organizational support, procedural justice and distributive justice. Ram and Prabhakar (2011) added job characteristics and rewards (intrinsic and extrinsic) as antecedents of employee engagement. Pandey and David (2013) posited three antecedents: satisfactory work environment, job enrichment and career growth opportunities. Other antecedents added by Olivier and Rothmann (2007) are psychological meaningfulness, safety and availability. Naidoo and Martins (2014) proposed organizational culture as an antecedent of employee engagement. Muthuveloo, Basbous, Ping and Long (2013) identified extended employee care, reward and recognition, employee development and employee communication as antecedents of employee engagement, which then give rise to organizational performance. The focus of other research studies has been on the mediating effect of engagement in the relationship between its antecedents and consequences, such as job satisfaction, involvement, organizational citizenship behaviour and intention to quit (Kumar \& Swetha, 2011; Ram \& Prabhakar, 2011).

For this study, 12 antecedents of employee engagement, as depicted in previous studies, were selected to test their effect on one of its consequences (i.e. job satisfaction) with employee engagement as a mediating variable in academic settings in Jordan. The main contribution of this study lies in the number of antecedents of employee engagement examined and the mediating effect of employee engagement. The study re-examined the results of more than 30 related works to verify to as great an extent as possible the organizational contracts that contribute towards employee engagement, which in turn triggers employees' satisfaction with their jobs. The ultimate beneficiaries of such findings are organizations, namely academic institutions, concerned about their success. The remainder of the paper is organized as follows: section two reviews the 
literature and shows the development of the study hypotheses. The methodology, encompassing the research design, the study sample, measures, research framework, validity and reliability of measurements and the characteristics of participants, are presented in section three. Section four is dedicated to the data analysis and results. It contains descriptive and inferential statistics for the study variables. The findings of the study are discussed in section five, in which conclusions are also drawn. Finally, the limitations and directions for future research are set out in section six.

\section{Literature review and hypotheses}

The aim of this section is to provide a critical review of the literature on the constructs comprising the antecedents and consequences of employee engagement - in relation to the latter, job satisfaction in particular - and the relationships pointed out between these constructs.

\subsection{Antecedents of employee engagement}

Dharmendra and Naveen (2013) listed the following antecedents of employee engagement: relationships among co-workers and team members, employees' pride in their organization, clear career growth opportunities, nature of the job, managers' trust and integrity and the clear contribution of employee performance to the organization's performance. The authors add more drivers of employee engagement, which are: effective leadership, motivation, rewards and recognition, clear job expectations, as well as feedback and mentoring. Taghipour and Dezfuli (2013) tested a model of work engagement consisting of work motivation, morale climate, psychological empowerment and job satisfaction. Their results revealed significant relationships between these variables and employee engagement. Employee communication has a significant relationship with employee engagement (AbuKhalifeh \& Som, 2013). Ferreira and Oliveira (2014) conducted a survey to examine the impact of corporate social responsibility (CSR)- general, internal and external - on employee engagement. Their results indicated that internal CSR practices have more impact than external CSR practices on employee engagement levels. Suharti and Suliyanto (2012) confirmed the effect of both organizational culture and leadership style on employee engagement. Kumar and Swetha (2011) proposed four antecedents of employee engagement: job characteristics, organizational and supervision support, organizational justice and rewards and recognition. Consistent with Shuck, Reio and Rocco (2011), Naidoo and Martins (2014) demonstrated a statistically significant relationship between organizational culture and employee engagement. Alabsi and Aamer (2014) examined the impact of employee involvement, clarity of the job role and organizational support on employee engagement in the Yemeni service sector, finding that all these variables are positively correlated with employee engagement. Concurrently, Jose and Mampilly(2014) found that psychological empowerment is related to employee engagement. Based on the above, the following hypotheses are proposed:

H1: $\quad$ Employee engagement is a response to employee communication.

H2: $\quad$ Employee engagement is a response to clear career growth opportunities.

H3: Employee engagement is a response to employees' pride in the organization.

H4: Employee engagement is a response to managers' trust and integrity. 
H5: Employee engagement is a response to rewards and recognition.

H6: $\quad$ Employee engagement is a response to feedback and mentoring.

H7: $\quad$ Employee engagement is a response to work motivation.

H8: $\quad$ Employee engagement is a response to psychological empowerment.

H9: $\quad$ Employee engagement is a response to internal CSR practices.

H10: Employee engagement is a response to organizational and supervisory support.

H11: Employee engagement is a response to organizational justice.

H12: Employee engagement is a response to organizational culture.

\subsection{Employee engagement consequences}

According to Truss, Shantz, Soane, Alfes. and Alfesd (2013), employee engagement can significantly predict organizational performance. Schaufeli, Salanova, Gonzalez-Roma and Bakker (2002) found evidence of a relationship between employee engagement and employee productivity. Hart, Caballero and Cooper (2010) examined both the antecedents and consequences of employee engagement in the academic context. They found that the dimensions of employee engagement (individual morale, workgroup morale, affective commitment, continuous commitment and job involvement) mediate the relationship between psychological climate (work environment) and performance-related outcomes, such as engaging practice, a focus on student wellbeing, teaching quality, teaching confidence, research confidence and research quality.

Suharti and Suliyanto (2012) reported an effect of employee engagement on employee loyalty. Moura et al. (2014) found that both role stress and employee engagement were significant predictors of job satisfaction. Ram and Prabhakar (2011) confirmed the hypothesis that employee engagement prompts organizational outcomes such as job satisfaction and involvement. Javadi and Ahmadi (2013) identified employee engagement as an antecedent of knowledge transfer. Albdour and Altarawneh (2014) investigated the relationship between employee engagement (job and organizational engagement) and organizational commitment (affective, continuous and normative) in Jordanian banks. The results showed an incremental relationship between these constructs. Anderson (2014) found a positive relationship between employee engagement and job satisfaction. According to Orgambídez-Ramos et al. (2014), job satisfaction can significantly be predicted by employee engagement. Therefore, the following hypothesis is suggested:

H13: Job satisfaction is a response to employee engagement.

\subsection{Employee engagement as a mediator}

For researchers to test the effect of a mediating variable in the relationship between independent and dependent variables, three conditions should be met (Alias, Noor \& Hassan, 2014): there should be a direct relationship between the independent variable and the dependent variable, a direct relationship between the independent variable and the mediating 
variable and a direct relationship between the mediating variable and the dependent variable. In a study conducted in Indonesia in the hotel sector, Suharti and Suliyanto (2012) found that employee engagement mediates the effect of organizational culture and leadership style on employee loyalty.

Ram and Prabhakar (2011) studied the mediating role of employee engagement in the relationships between potential antecedents of engagement and work-related outcomes such as job satisfaction and involvement. The authors studied four antecedents: job characteristics, rewards, organizational and supervisory support and employees' perceptions of organizational justice. Using a sample of 310 subjects working for Jordanian hotels, their findings confirmed the effect of all these variables on employee engagement, which in turn predicts the stated organizational outcomes. Anderson (2014) verified the mediating effect of employee engagement in the relationship between hindrances and challenging demands, high involvement and workgroup outcomes (i.e. job satisfaction, productivity and safety). Based on the above, the following hypothesis is proposed:

H14: Employee engagement is a response to its antecedents and predicts job satisfaction.

\section{Methodology}

\subsection{Research design, sample and measures}

This research comprised a quantitative cross-sectional survey undertaken with a sample of 250 employees randomly selected from academic institutions in Jordan. of the 250 questionnaires distributed, 238 valid responses were returned for statistical analysis. The data collected were analysed using the AMOS (V.16) and SPSS (V.20) packages. A five-point Likert scale developed by Saks (2006) was used to measure employee engagement. This has previously been used by Sze and Angeline (2011) and Albdour and Altarawneh (2014).

The antecedents of employee engagement were measured using a questionnaire developed based on previous research studies, such as those of Spreitzer (1995), Farndale et al. (2014), Rasheed and Khan (2013), Ram and Prabhakar (2011), Pandey and David (2013), Shafi et al. (2013), Sarwar and Abugre (2013), Naidoo and Martins (2014), Muthuveloo et al. (2013), Jose and Mampilly (2014), Hart et al. (2010), Ferreira and Oliveira (2014) and AbuKhalifeh and Som (2013). 


\subsection{Research framework}

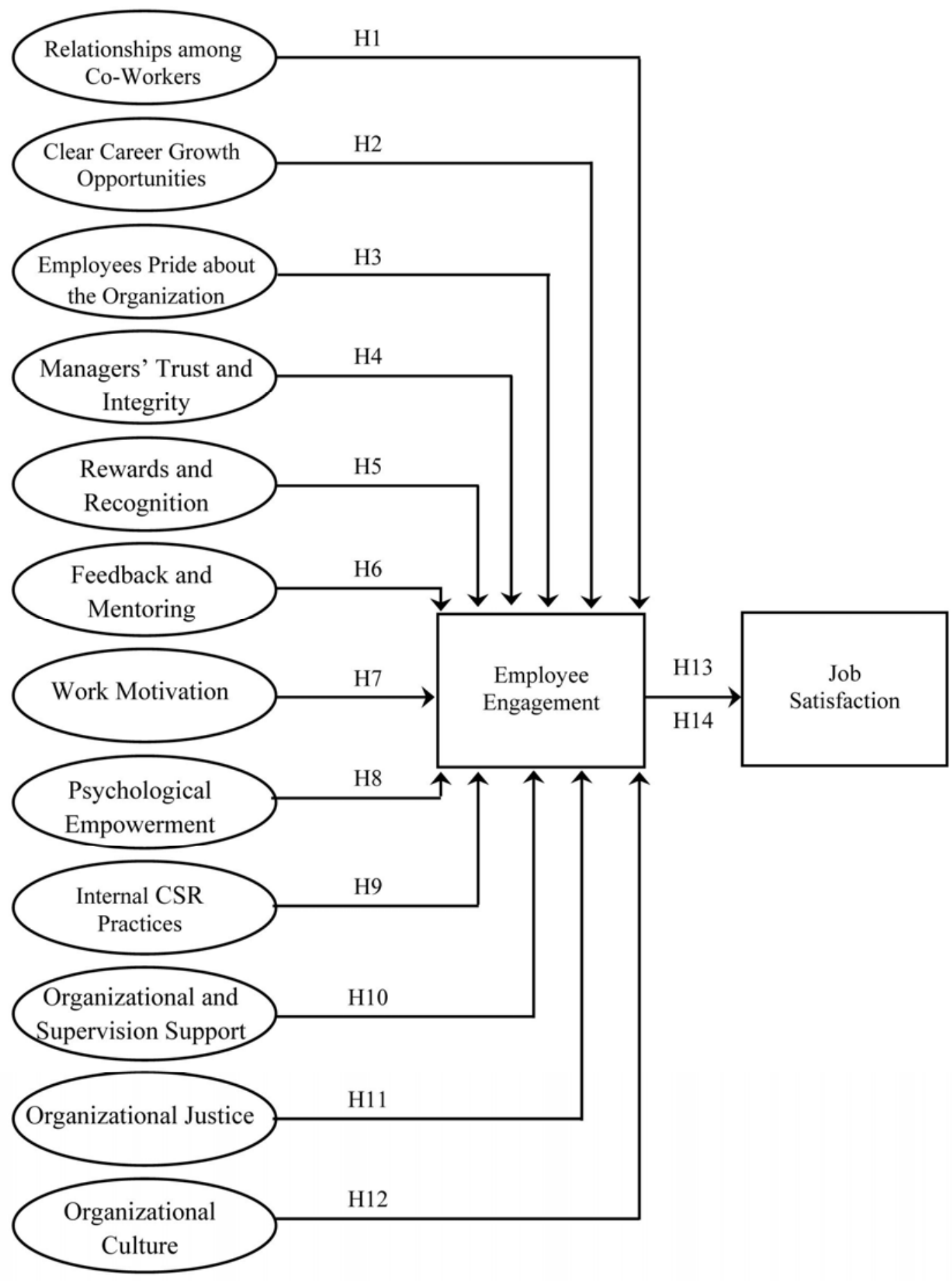

Figure 1. Research framework 


\subsection{Validity and reliability}

Three measurements were used in this study: antecedents of employee engagement (AEE), employee engagement (EE) and job satisfaction (JS). All measurements showed acceptable validity and reliability according to the chi-squared statistic $\left(\chi^{2} / d f<2\right)$, the comparative fit index (CFI $>0.90$ ), root mean square error of approximation (RMSEA $<0.08), p<0.01$, as well as the values of Cronbach's alpha coefficient alpha $(\alpha>0.7)$. Table 1 shows the results for all constructs.

Table 1. Reliability of measurements

\begin{tabular}{lcccccc}
\hline No. & Construct & Cronbach's alpha & $\chi^{2} / d f$ & $\mathrm{p}$ & RMSEA (90\% CI) & CFI \\
\hline 1 & AEE & 0.87 & 1.21 & 0.000 & 0.072 & 0.98 \\
2 & EE & 0.83 & 1.36 & 0.000 & 0.73 & 0.94 \\
3 & JS & 0.78 & 1.42 & 0.000 & 0.68 & 0.93 \\
\hline
\end{tabular}

\subsection{Characteristics of subjects}

As shown in Table 2, 137 (58\%) of the study respondents were male and 101 (42\%) were female. In terms of age, 66 (28\%) of the participants fell into 41-45 year age category. In terms of educational level, $72(30 \%)$ held a four-year degree and $85(36 \%)$ had a $\mathrm{PhD}$. The highest percentage for experience (31\%) was for participants within the 11-15 year category.

Table 2. Personal characteristics of respondents

\begin{tabular}{lll}
\hline Item & Category & Frequency (\%) \\
\hline Sex & Male & $137(58 \%)$ \\
& Female & $101(42 \%)$ \\
\hline Age & $25-30$ & $12(5 \%)$ \\
& $31-35$ & $38(16 \%)$ \\
& $36-40$ & $45(19 \%)$ \\
& $41-45$ & $66(28 \%)$ \\
& $46-50$ & $41(17 \%)$ \\
& $51-60$ & $29(12 \%)$ \\
\hline Education & 61 or above & $7(3 \%)$ \\
& Less than 4 years degree & $48(20 \%)$ \\
& Bachelor & $72(30 \%)$ \\
& Master & $33(14 \%)$ \\
Experience & Ph.D. & $85(36 \%)$ \\
& $1-5$ & $28(12 \%)$ \\
& $6-10$ & $58(24 \%)$ \\
& $11-15$ & $74(31 \%)$ \\
\hline Total & $16-20$ & $54(23 \%)$ \\
& 21 years or above & $24(10 \%)$ \\
\hline
\end{tabular}




\section{Al Macrothink}

\section{Results}

\subsection{Descriptive and inferential statistics}

Based on Naidoo and Martins (2014), mean scores greater than 3.2 were used to identify the positive perceptions of participants on scale dimensions. As can be seen from Table 3, the range of mean scores for the antecedents of employee engagement was between 3.613 and 4.110, which means that levels of these antecedents were above average and high. The lowest score was for internal CSR practices and the highest was for rewards and recognition. The mean scores for employee engagement and job satisfaction were 3.774 and 3.827 respectively.

Table 3. Means, standard deviations

\begin{tabular}{lccc}
\hline Variables & $\mathrm{N}$ & $\mathrm{M}$ & $\mathrm{SD}$ \\
\hline 1. Employee communication & 238 & 3.985 & 0.841 \\
2. Career growth opportunities & 238 & 3.714 & 0.974 \\
3. Employees pride about the organization & 238 & 3.761 & 0.952 \\
4. Managers' trust and integrity & 238 & 3.788 & 0.851 \\
5. Rewards and recognition & 238 & 4.110 & 0.722 \\
6. Feedback and mentoring & 238 & 3.683 & 0.697 \\
7. Work motivation & 238 & 3.628 & 0.753 \\
8. psychological empowerment & 238 & 3.772 & 0.658 \\
9. internal CSR practices & 238 & 3.613 & 0.814 \\
10. organizational and supervision support & 238 & 3.908 & 0.742 \\
11. organizational justice & 238 & 3.814 & 0.589 \\
12. organizational culture & 238 & 3.663 & 0.788 \\
13. employee engagement & 238 & 3.774 & 0.921 \\
14. job satisfaction & 238 & 3.827 & 1.201 \\
\hline *p $<0.05, * * p<0.01$ & & & \\
\hline
\end{tabular}

\subsection{Pearson's product-moment correlation coefficient}

An inter-correlation matrix was calculated to evaluate relationships between variables. As demonstrated in Table 4, there are significant relationships between the dimensions of the antecedents of employee engagement and employee engagement: employee communication $(\mathrm{r}=$ $0.74, \mathrm{p}<0.05)$, career growth opportunities $(\mathrm{r}=0.62, \mathrm{p}<0.05)$, employees' pride in the 
organization $(r=0.47, p<0.05)$, managers' trust and integrity $(r=0.48, p<0.05)$, rewards and recognition $(r=0.64, p<0.05)$, feedback and mentoring $(r=0.72, p<0.05)$, work motivation ( $r$ $=0.51, \mathrm{p}<0.05)$, psychological empowerment $(\mathrm{r}=0.44, \mathrm{p}<0.05)$, internal CSR practices $(\mathrm{r}=$ $0.57, \mathrm{p}<0.05)$, organizational and supervision support $(\mathrm{r}=0.68, \mathrm{p}<0.05)$, organizational justice $(\mathrm{r}=0.53, \mathrm{p}<0.05)$ and organizational culture $(\mathrm{r}=0.49, \mathrm{p}<0.05)$.

Table 4. Inter-correlations between variables

\begin{tabular}{ccccccccccccccc}
\hline & 1 & 2 & 3 & 4 & 5 & 6 & 7 & 8 & 9 & 10 & 11 & 12 & 13 & 14 \\
\hline 1 & - & & & & & & & & & & & & \\
2 & 0.39 & - & & & & & & & & & & & \\
3 & 0.57 & 0.42 & - & & & & & & & & & & \\
4 & 0.61 & 0.35 & 0.51 & - & & & & & & & & & \\
5 & 0.51 & 0.46 & 0.41 & 0.51 & - & & & & & & & & \\
6 & 0.42 & 0.51 & 0.52 & 0.62 & 0.58 & - & & & & & & & \\
7 & 0.42 & 0.45 & 0.61 & 0.52 & 0.78 & 0.79 & - & & & & & & \\
8 & 0.43 & 0.30 & 0.35 & 0.71 & 0.46 & 0.68 & 0.71 & - & & & & & \\
9 & 0.54 & 0.41 & 0.55 & 0.43 & 0.72 & 0.54 & 0.52 & 0.57 & - & & & & \\
10 & 0.60 & 0.64 & .47 & 0.42 & 0.50 & 0.37 & 0.30 & 0.59 & 0.64 & - & & & \\
11 & 0.43 & 0.57 & 0.48 & 0.34 & 0.54 & 0.41 & 0.54 & 0.70 & 0.62 & 0.49 & - & & \\
12 & 0.47 & 0.50 & 0.45 & 0.66 & 0.40 & 0.60 & 0.69 & 0.65 & 0.52 & 0.42 & 0.57 & - & \\
13 & 0.74 & 0.62 & 0.47 & 0.48 & 0.64 & 0.72 & 0.51 & 0.44 & 0.57 & 0.68 & 0.53 & 0.49 & - \\
14 & 0.63 & 0.71 & 0.54 & 0.55 & 0.78 & 0.68 & 0.74 & 0.60 & 0.71 & 0.63 & 0.47 & 0.59 & 0.78 & - \\
\hline
\end{tabular}

1: employee communication, 2: career growth opportunities, 3 : employees pride about the organization, 4 : managers' trust and integrity, 5: rewards and recognition, 6: feedback and mentoring, 7: work motivation, 8: psychological empowerment, 9: internal CSR practices, 10: organizational and supervision support, 11: organizational justice, 12: organizational culture, 13: employee engagement, 14: job satisfaction.

$\mathrm{p}<0.05$

Equally, all antecedents were positively correlated with job satisfaction: employee communication $(r=0.63, p<0.05)$, career growth opportunities $(r=0.71, p<0.05)$, employees' pride in the organization $(\mathrm{r}=0.54, \mathrm{p}<0.05)$, managers' trust and integrity $(\mathrm{r}=0.55, \mathrm{p}<0.05)$, rewards and recognition $(r=0.60, p<0.05)$, feedback and mentoring $(r=0.68, p<0.05)$, work motivation $(r=$ $0.74, \mathrm{p}<0.05)$, psychological empowerment $(\mathrm{r}=0.78, \mathrm{p}<0.05)$, internal CSR practices $(\mathrm{r}=0.71$, $\mathrm{p}<0.05)$, organizational and supervision support $(\mathrm{r}=0.63, \mathrm{p}<0.05)$, organizational justice $(\mathrm{r}=$ $0.47, \mathrm{p}<0.05)$ and organizational culture $(\mathrm{r}=0.59, \mathrm{p}<0.05)$. Finally, the above table illustrates that employee engagement is positively correlated with job satisfaction $(r=0.78, p<0.05)$. On the strength of the above results, all hypotheses H1, H2, H3, H4, H5, H6, H7, H8, H9, H10, H11 and H12 are accepted. That is, all the antecedents of employee engagement are positively related to employee engagement. Moreover, the results show that employee engagement is positively related to job satisfaction, providing support for H13. 


\subsection{Multiple regression analysis}

Multiple regression analysis was conducted to test the hypothesis that employee engagement mediates the effect of the antecedents of employee engagement on job satisfaction. According to Alias et al. (2014), three paths should be examined to verify the effect of the mediating variable. Path 1 assumes that the independent variable predicts the dependent variable. As shown in Table 5, all the antecedents of employee engagement explain 58\% of the variability in job satisfaction $\left(\mathrm{R}^{2}=0.557, \mathrm{~F}=11.23, \mathrm{p}<0.05\right)$. That is, the antecedents of employee engagement significantly predict job satisfaction. The coefficients of the regression indicate that rewards and recognition have the greatest effect on job satisfaction $(\beta=0.481, t=9.216, p$ $<0.05)$ and the lowest effect is for employees' pride in the organization $(\beta=0.227, \mathrm{t}=3.513, \mathrm{p}<$ 0.05 ). The table also shows that the beta values for other predictors range from 0.320 to 0.472 .

Table 5. Regression results for predictors and job satisfaction

\begin{tabular}{cccc}
\hline Model summary & \multicolumn{3}{c}{ ANOVA } \\
\hline $\mathrm{r}$ & $\mathrm{R}^{2}$ & $\mathrm{~F}$ & $\mathrm{P}$ \\
\hline 0.76 & 0.577 & 11.23 & 0.000 \\
\hline \multicolumn{5}{c}{ Coefficients } & $\mathrm{t}$ & $\mathrm{P}$ \\
\hline constant & $\mathrm{B}$ & 1.241 & 0.271 \\
1 & - & 4.591 & 0.000 \\
2 & 0.421 & 6.120 & 0.001 \\
3 & 0.441 & 3.513 & 0.000 \\
4 & 0.227 & 3.611 & 0.010 \\
5 & 0.320 & 9.216 & 0.000 \\
6 & 0.481 & 5.019 & 0.000 \\
7 & 0.439 & 7.111 & 0.003 \\
8 & 0.472 & 4.019 & 0.000 \\
9 & 0.398 & 5.991 & 0.020 \\
10 & 0.462 & 4.997 & 0.000 \\
11 & 0.437 & 5.801 & 0.010 \\
12 & 0.433 & 4.110 & 0.000 \\
\hline
\end{tabular}

Predictors: (constant), 1: employee communication, 2: career growth opportunities, 3: employees pride about the organization, 4: managers' trust and integrity, 5: rewards and recognition, 6: feedback and mentoring, 7: work motivation, 8: psychological empowerment, 9: internal CSR practices, 10: organizational and supervision support, 11: organizational justice, 12: organizational culture, 13: employee engagement, 14: job satisfaction.

Dependent variable: job satisfaction

Path 2 proposes an effect of the predictor variables on the mediator variable (employee engagement). As shown in Table 6, all independent variables explain around $80 \%$ of the variability in employee engagement $\left(\mathrm{R}^{2}=0.896, \mathrm{~F}=13.87, \mathrm{p}<0.05\right)$. On the basis of the 
regression coefficients, psychological empowerment has the greatest effect on employee engagement $(\beta=0.407, \mathrm{t}=7.151, \mathrm{p}<0.05)$, while internal CSR practices have the lowest effect on employee engagement $(\beta=0.198, \mathrm{t}=3.661, \mathrm{p}<0.05)$. Other coefficients indicate different degrees of predictors' contribution to employee engagement.

Table 6. Regression results for predictors and employee engagement

\begin{tabular}{|c|c|c|c|}
\hline \multicolumn{2}{|c|}{ Model summary } & \multicolumn{2}{|c|}{ ANOVA } \\
\hline $\mathrm{r}$ & $\mathrm{R}^{2}$ & $\mathrm{~F}$ & $\mathrm{P}$ \\
\hline 0.896 & 0.802 & 13.87 & 0.000 \\
\hline \multicolumn{4}{|c|}{ Coefficients } \\
\hline & $\mathrm{B}$ & $\mathrm{t}$ & $\mathrm{P}$ \\
\hline constant & - & 1.106 & 0.320 \\
\hline 1 & 0.341 & 6.177 & 0.000 \\
\hline 2 & 0.365 & 6.801 & 0.000 \\
\hline 3 & 0.297 & 4.320 & 0.000 \\
\hline 4 & 0.396 & 7.557 & 0.000 \\
\hline 5 & 0.400 & 6.124 & 0.003 \\
\hline 6 & 0.311 & 5.110 & 0.000 \\
\hline 7 & 0.358 & 6.311 & 0.000 \\
\hline 8 & 0.407 & 7.151 & 0.000 \\
\hline 9 & 0.198 & 3.661 & 0.002 \\
\hline 10 & 0.213 & 8.119 & 0.000 \\
\hline 11 & 0.319 & 7.994 & 0.001 \\
\hline 12 & 0.388 & 8.451 & 0.000 \\
\hline
\end{tabular}

Predictors: (constant), 1: employee communication, 2: career growth opportunities, 3: employees pride about the organization, 4: managers' trust and integrity, 5: rewards and recognition, 6: feedback and mentoring, 7: work motivation, 8: psychological empowerment, 9: internal CSR practices, 10: organizational and supervision support, 11: organizational justice, 12: organizational culture, 13: employee engagement, 14: job satisfaction.

Dependent variable: employee engagement

Path 3 hypothesizes an effect of the mediator variable (employee engagement) on the dependent variable (job satisfaction). As displayed in Table 7, employee engagement explains approximately $44 \%$ of the variance in job satisfaction $\left(R^{2}=0.440, F=28.12, p<0.05\right)$. The results confirm the significant effect of employee engagement in predicting job satisfaction $(\beta=$ $0.709, \mathrm{t}=17.620, \mathrm{p}<0.05)$. In conclusion, all hypothesized relationships between the study variables are supported. In particular, employee engagement mediates the effect of its antecedents on job satisfaction (H14). 
Table 7. Regression results for employee engagement and job satisfaction

\begin{tabular}{cccc}
\hline \multicolumn{2}{c}{ Model summary } & \multicolumn{3}{c}{ ANOVA } \\
\hline $\mathrm{r}$ & $\mathrm{R}^{2}$ & $\mathrm{~F}$ & $\mathrm{P}$ \\
\hline 0.664 & 0.440 & 28.12 & 0.000 \\
\hline & & Coefficients & $\mathrm{P}$ \\
\hline & $\mathrm{B}$ & $\mathrm{t}$ & 0.000 \\
Employee engagement & - & 6.208 & 0.000 \\
\hline
\end{tabular}

Predictors: (constant), employee engagement

Dependent variable: job satisfaction

\section{Discussion and conclusion}

This study was designed to demonstrate the mediating effect of employee engagement between its antecedents and consequences and to test the effect of employee engagement on job satisfaction. The results confirm all the hypothesized relationships, namely co-workers' relationships, clear career growth opportunities, employees' pride in their organization, managers' trust and integrity, rewards and recognition, feedback and mentoring, work motivation, psychological empowerment, internal CSR practices, organizational and supervisory support, organizational justice and organizational culture are positively associated with employee engagement, which in turn predicts job satisfaction. Similar findings have been foundin previous research studies. The hypothesis that employee communication is positively related to employee engagement is supported by AbuKhalifeh and Som (2013). According to Muthuveloo et al. (2013), employee development is the most significant predictor of employee engagement. Pandey and David (2013) also suggested that opportunities to grow trigger employee engagement. According to Vance (2006), employees' pride in their organization will increase their engagement. Managers' trust and integrity has also been found to be one of the top drivers of employee engagement (Gibbons, 2006). Muthuveloo et al. (2013) pointed out that higher rewards and recognition result in higher levels of employee engagement. Sarwar and Abugre (2013) reported that positive feedback drives employee engagement.

Shafi et al. (2013) demonstrated that mentoring has a positive impact on employee engagement. The correlation between work motivation and employee engagement was studied and confirmed by Taghipour and Dezfuli (2013). Psychological empowerment is one of predictors stated by Jose and Mampilly (2014) as a significant antecedent of employee engagement. Inconsistent with Ferreira and Oliveira (2014), in this study internal CSR practices were found to be positively related to employee engagement. One of the results found by Rich et al. (2010) was that higher levels of organizational support contribute to higher levels of employee engagement. The positive relationship between supervisory support and employee engagement was shown by Rasheed and Khan (2013).Rasheed and Khan (2013) also found acceptance for the hypothesis of a relationship between organizational justice and employee engagement, demonstrating that they are positively linked. Gupta et al. (2015) carried out a study to identify 
variables affecting employee engagement in financial organizations in India. According to their results, organizational culture affects employee engagement. On the correlation between employee engagement and job satisfaction, Farndale et al. (2014) confirmed that one of the employee outcomes (i.e. job satisfaction) is related to employee engagement. Likewise, Anderson (2014) and Orgambídez-Ramos et al. (2014) found a positive link between employee engagement and job satisfaction. In Moura et al.'s (2014) study, job satisfaction was significantly predicted by employee engagement. In conclusion, this study contributes to the literature by identifying the drivers of employee engagement as well as its outcomes in academic institutions in Jordan. The practical implications of this study are that accommodations should be made for employees in relation to the aforementioned antecedents of employee engagement to stimulate employee job satisfaction.

\section{Limitations and future research}

One of the key limitations of this study is the cross-sectional design employed. According to Albdourand Altarawneh (2014), such a research design cannot reflect changes in variables overtime. Another limitation concerns the size of the sample selected, which in turn affects the generalizability of the study findings. Further research is required to study the relationships between variables such as employee communication and employee engagement and the impact on other variables such as productivity, performance and organizational citizenship behaviour.

\section{References}

AbuKhalifeh, A., \& Som, A. (2013). The Antecedents Affecting Employee engagement and Organizational Performance. Asian Social Science, 9(7), 41-46, http://dx.doi.org/10.5539/ass.v9n7p41.

Alabsi, A., \& Aamer, A. (2014). Employee Engagement: The Case of Service Industry in Yemen. Middle-East Journal of Scientific Research, 22(7), 1014-1024.

Albdour, A., \& Altarawneh, I. (2014). Employee Engagement and Organizational Commitment: Evidence from Jordan. International Journal of Business, 19(2), 192-212.

Alias, N., Noor, N., \& Hassan, R. (2014). Examining the Mediating Effect of Employee Engagement on the Relationship between Talent Management Practices and Employee Retention in the Information and Technology Organizations in Malaysia. Journal of Human Resources Management and Labor Studies, 2(2), 227-242.

Anderson, S. (2014). The Moderating Effect of Within-Team Trust on Employee Engagement and Workgroup Outcomes. Proceedings of the Fourth International Conference on Engaged Management Scholarship, Tulsa, OK, September 10-14. http://dx.doi.org/10.2139/ssrn.2555706

Coetzee, M., \& De Villiers, M. (2010). Sources of Job Stress, Work Engagement and Career Orientations of Employees in South African Financial Institution, Southern African Business Review, 14(1), 27-58. 
Dharmendra, \& Naveen, K (2013). Employee Engagement: A Literature Review. Economia, Seria Management, 16(2), 208-215.

Farndale, E., Beijer, S., Veldhoven, M., Kelliher, C., \& Hope-Hailey, V. (2014). Work and Organization Engagement: Aligning Research and Practice. Journal of Organizational Effectiveness: People and Performance, 1(2), 157-176, http://dx.doi.org/10.1108/JOEPP-03-2014-0015.

Ferreira, P., \& Oliveira, E. (2014). Does Corporate Social Responsibility Impact on Employee Engagement?. Journal of Workplace Learning, 26(3/4), 232-248, http://dx.doi.org/10.1108/JWL-09-2013-0070

Gibbons, J. (2006). Employee Engagement: A Review of Current Research and Its Implications. NY: The Conference Board Inc.

Gupta, M., V, Sh., \& Ponnam, A. (2015). Factors Affecting Employee Engagement in India: A Study on Off-Shoring of Financial Services. The Qualitative Report, 20(4:8), 498-515.

Hart, P., Caballero, C., \& Cooper, W. (2010). Understanding Engagement: Its Structure, Antecedents and Consequences. International Academy of Management and Business Summer Conference, Madrid, 21-23 June.

Javadi, M., \& Ahmadi, A. (2013). Investigating the Roles of Organizational Culture, Leadership Style, and Employee Engagement in Knowledge Transfer. International Journal of Academic Research in Business and Social Sciences September, 3(9), 717-734, http://dx.doi.org/10.6007/IJARBSS/v3-i9/261

Jose, G., \& Mampilly, S. (2014). Psychological Empowerment as a Predictor of Employee Engagement: An Empirical Attestation. Global Business Review, 15(1), 93-104, http://dx.doi.org/10.1177/0972150913515589.

Kahn W. (1990). Psychological Conditions of Personal Engagement and Disengagement at Work. Academy of Management Journal, 33, 692-724. http://dx.doi.org/10.2307/256287

Kumar, D., \& Swetha, G. (2011). A Prognostic Examination of Employee Engagement from Its Historical Roots. International Journal of Trade, Economics and Finance, 2(3), 232-241. http://dx.doi.org/10.7763/IJTEF.2011.V2.108

May, D., Gilson, R., \& Harter, L. (2004). The Psychological Conditions of Meaningfulness, Safety and Availability and the Engagement of the Human Spirit at Work. Journal of Occupational and Organizational Psychology, 77, 11-37. http://dx.doi.org/10.1348/096317904322915892

Moura, D., Orgambídez-Ramos, A., \& Gonçalves, G. (2014). Role Stress and Work Engagement as Antecedents of Job Satisfaction: Results from Portugal. Europe's Journal of Psychology, 10(2), 291-300, http://dx.doi.org/10.5964/ejop.v10i2.714 
Muthuveloo, R., Basbous, O., Ping, T., \& Long, C. (2013). Antecedents of Employee Engagement in the Manufacturing Sector. American Journal of Applied Sciences, 10(12), 1546-1552. http://dx.doi.org/10.3844/ajassp.2013.1546.1552.

Naidoo, P., \& Martins, N. (2014). Investigating the Relationship between Organizational Culture and Work Engagement. Problems and Perspectives in Management, 12(4), 433-441.

Olivier, A., \& Rothmann, S. (2007). Antecedents of Work Engagement in a Multinational Oil Company, SA Journal of Industrial Psychology, 33(3), 49-56. http://dx.doi.org/10.4102/sajip.v33i3.396

Orgambídez-Ramos, A., Borrego-Alés, Y., \& Mendoza-Sierra, I. (2014). Role stress and work engagement as antecedents of job satisfaction in Spanish workers. Journal of Industrial Engineering and Management, 7(1), 360-372, http://dx.doi.org/10.3926/jiem.992.

Pandey, S., \& David, S. (2013). A Study of Engagement at Work: What drives Employee Engagement?. European Journal of Commerce and Management Research (EJCMR), 2(7), 155-161.

Ram, P., \& Prabhakar, G. (2011). The Role of Employee Engagement in Work-Related Outcomes. Interdisciplinary Journal of Research in Business, 1(3), 47-61.

Rasheed, A., \& Khan, S. (2013). Antecedents and Consequences of Employee Engagement: The Case of Pakistan. Journal of Business Studies Quarterly, 4(4), 183-200.

Rich, B., Lepine, J., \& Crawford, E. (2010). Job Engagement: Antecedents and Effects on Job Performance. Academy of Management Journal, 53(3), 617-635. http://dx.doi.org/10.5465/AMJ.2010.51468988

Saks, A. (2006). Antecedents and Consequences of Employee Engagement. Journal of Managerial Psychology, 21(7), 600-619. http://dx.doi.org/10.1108/02683940610690169

Sarwar, S., \& Abugre, J. (2013). Does Provision of Feedback Increase Work Engagement and Reduce Cynicism among Employees?. The Business \& Management Review, 3(4), 20-31.

Schaufeli, W., \& Bakker, A. (2004). Job Demands, Job Resources and Their Relationship with Burnout and Engagement: A Multi-Sample Study. Journal of Organizational Behavior, 25, 293-315. http://dx.doi.org/10.1002/job.248

Schaufeli, W., Salanova, M., Gonzalez-Roma, V., \& Bakker, A.(2002). The Measurement of Engagement and Burnout: A Two Sample Confirmatory Factor Analytic Approach. Journal of Happiness Studies, 3, 71-92. http://dx.doi.org/10.1023/A:1015630930326

Shafi, S., Zaigham , S., Ahmed, H., Saeed, H., Jahangir , H., \& Ullah, Z. (2013). Relationship of Communication, Mentoring and Socialization with Employee Engagement. European Journal of Business and Social Sciences, 2(3), 17-36, http://www.ejbss.com/recent.aspx. 


\section{Macrothink}

Journal of Management Research

ISSN 1941-899X 2015, Vol. 7, No. 5

Shuck, B., Reio, T., \& Rocco, T. (2011). Employee Engagement: An Examination of Antecedent and Outcome Variables. Human Resource Development International, 14(4), 427-445. http://dx.doi.org/10.1080/13678868.2011.601587

Spreitzer, G. (1995). Individual Empowerment in the Workplace: Dimensions, Measurement, Validation. Academy of Management Journal, 38, 1442-1465. http://dx.doi.org/10.2307/256865

Suharti, L., \& Suliyanto, D. (2012). The Effects of Organizational Culture and Leadership Style Toward Employee Engagement and Their Impacts Toward Employee Loyalty. World Review of Business Research, 2(5), 128-139.

Sze, C., \& Angeline, T. (2011). Engaging Employees to Their Jobs: Role of Exchange Ideology as a Moderator. African Journal of Business Management, 5(10), 3986-3994, http://dx.doi.org/10.5897/AJBM11.215.

Taghipour, A., \& Dezfuli, Z. (2013). Designing and Testing a Model of Antecedents of Work Engagement. Social and Behavioral Sciences, 84, 149-154.

Trussa, C., Shantz, A., Soane, E., Alfes, K., \& Alfesd, R. (2013). Employee Engagement, Organizational Performance and Individual Well-Being: Exploring the Evidence, Developing the Theory. The International Journal of Human Resource Management, 24(14), 2657-2669. http://dx.doi.org/10.1080/09585192.2013.798921

Vance, R. (2006). Employee Engagement and Commitment: A Guide to Understanding, Measuring and Increasing Engagement in Your Organization. USA: SHRM Foundation. SHRM Online - Society for Human Resource Management - http://www.shrm.org. 